\section{Anafilaxia relacionada à vacina sarampo, caxumba e rubéola, Santa Catarina, Brasil, 2014 e 2015}

Anaphylaxis related to measles, mumps, and rubella vaccine in Santa Catarina State, Brazil, 2014 and 2015

\section{Anafilaxia relacionada a la vacuna sarampión, paperas y rubeola, Santa Catarina, Brasil, 2014 y 2015}

\author{
Francieli Fontana Sutile Tardetti Fantinato 1 \\ Alexander Vargas 1 \\ Sandra Maria Deotti Carvalho 1 \\ Carla Magda Allan Santos Domingues 1 \\ Gisele Barreto 2 \\ Arieli Schiessl Fialho 2 \\ Roselita Heinen da Silva 2 \\ Eduardo Saad 1 \\ Ivonne Natalia Solarte Agredo 1
}

doi: 10.1590/0102-311X00043617

\section{Correspondência}

F. F. S. T. Fantinato

QMSW 5, Lote 2, apto. D 209, Brasília, DF 70680-500, Brasil.

francifontana7@gmail.com

Os objetivos consistiram em descrever os casos e verificar a frequência de
anafilaxia relacionada à vacina sarampo, caxumba e rubéola (SCR) do produtor A, bem como avaliar os possíveis fatores de risco associados. Estudo de caso-controle (1:4), em Santa Catarina, Brasil, de 14 de julho de 2014 a 12 de janeiro de 2015, em crianças de um a menores de cinco anos, vacinadas com SCR e notificadas com anafilaxia, sendo os controles sem anafilaxia. Utilizou-se, como medida de associação, odds ratio (OR) com intervalo de 95\% de confiança (IC95\%) e os testes qui-quadrado e exato de Fisher. Calcularam-se taxas de anafilaxia por doses distribuidas/aplicadas. Entrevistaram-se $15 \mathrm{ca}$ sos e 60 controles, em 12 municípios. As taxas de anafilaxia foram 2,46 e 5,05 por doses distribuídas e aplicadas, respectivamente. Dentre os casos de anafilaxia, oito $(53,4 \%)$ eram do sexo masculino, e dentre os controles, 36 (60\%), $\operatorname{com} p=0,64$. Na análise bivariada referente à anafilaxia e alergia à proteína do leite de vaca $(A P L V)$, verificou-se OR $=51,62$, com $p=0,00002$ e IC95\%: 5,59-476,11. As variáveis alergia alimentar familiar, aleitamento materno, evento adverso pós-vacinação (EAPV) anterior e vacinação simultânea não foram estatisticamente significativas ( $p=0,48 ; p=1,00 ; p=0,49 ; p=0,61$ ). Taxas de anafilaxia por doses distribuídas/aplicadas ficaram acima de 1/100 mil doses aplicadas (taxa esperada). Anafilaxia e APLV apresentaram associação estatisticamente significativa. Não foram encontradas associações estatísticas referentes à vacinação simultânea, aleitamento materno, alergia alimentar familiar e EAPV anterior. Recomendou-se ao produtor informar na bula todos os componentes do produto e que crianças com história pregressa de APLV não sejam vacinadas com essa vacina.

Vacina Contra Sarampo-Caxumba-Rubéola; Vacinação; Anafilaxia; Criança
1 Ministério da Saúde, Brasília, Brasil.

2 Secretaria de Estado da Saúde de Santa Catarina,

Florianópolis, Brasil. 


\section{Introdução}

As vacinas, como quaisquer outros produtos biológicos, não estão livres de produzir efeitos indesejáveis e requerem atenção especial porque podem desencadear eventos adversos leves ou graves, esperados ou inusitados e que, se não forem identificados, investigados e acompanhados, levam a prejuízos na adesão ao programa de imunização 1,2 .

Evento adverso pós-vacinação (EAPV) é qualquer ocorrência médica indesejada após a vacinação e que não necessariamente possui relação causal com o uso da vacina ou outro imunobiológico ${ }^{3}$. Muitos dos eventos são meramente associações temporais, não se devendo à aplicação das vacinas. Assim, quando eles ocorrem, há necessidade de cuidadosa investigação, visando ao diagnóstico diferencial 4.

A vacina sarampo, caxumba e rubéola (SCR) - também conhecida como vacina tríplice viral - é uma vacina combinada que protege contra o sarampo, caxumba e rubéola, sendo pouco reatogênica e bem tolerada. Os eventos adversos decorrentes do uso dessa vacina ocorrem em maior intensidade por reações de hipersensibilidade a qualquer componente presente nela 4 e, dentre os mais graves, está a anafilaxia 5 .

Anafilaxia é uma reação aguda de hipersensibilidade, com envolvimento de múltiplos sistemas, de progressão rápida, grave e com risco de morte 6 . Sua ocorrência é rara, com uma incidência estimada para a vacina SCR de um caso por 100 mil doses aplicadas 7 .

No calendário nacional de vacinação do Ministério da Saúde, a vacina SCR está indicada a partir de um ano de idade 8 , e nas campanhas nacionais de seguimento contra o sarampo, o público-alvo é a criança de um a menor de cinco anos ${ }^{9}$, de acordo com a situação epidemiológica e acúmulo de suscetíveis ao longo dos anos. Na faixa etária de 10 a 19 anos, estão indicadas duas doses dessa vacina, e dos 20 aos 49 anos, uma dose 8 .

Durante a campanha nacional de seguimento contra o sarampo, realizada no ano de 2014, os estados brasileiros começaram a notificar a ocorrência de anafilaxia relacionada à vacina SCR do produtor A e informaram que essa reação estava ocorrendo principalmente em crianças com alergia à proteína do leite de vaca (APLV).

Nessa campanha, foi utilizada a vacina SCR de três produtores distintos, sendo distribuídas 19.169.011 milhões de doses, com o seguinte quantitativo por produtor: 17.657.753 (produtor A), 811.340 (produtor B) e 699.918 (produtor C). A distribuição da vacina SCR do produtor A iniciou-se no Brasil a partir de julho de 2014. A vacina dos demais produtores já era utilizada na rotina.

A Sociedade Brasileira de Alergia e Imunologia, por meio de consulta à Agência Nacional de Vigilância Sanitária (Anvisa), verificou a presença de lactoalbumina hidrolisada na composição da vacina do produtor A, a qual não constava na bula 10. Rumores em uma comunidade do Facebook (Põe no Rótulo; http://www.facebook.com/poenorotulo?ref=ts\&fref=ts) sobre relatos de "alergia a vacina $S C R$ do produtor A, relacionada à presença deste componente” também chamaram a atenção do Ministério da Saúde. Suspeitou-se, então, que os EAPV notificados poderiam estar relacionados à vacina SCR desse produtor. $\mathrm{Na}$ análise descritiva realizada anteriormente a este estudo, por meio do sistema de informação de EAPV e e-mails recebidos pelos estados, evidenciou-se que, dos casos notificados nas 27 Unidades Federadas do Brasil, uma parcela das crianças apresentava APLV e as taxas de anafilaxia referentes aos demais produtores encontravam-se dentro do esperado ${ }^{7}$.

Verificou-se ainda que o Estado de Santa Catarina apresentou o maior número de casos de anafilaxia (16), distribuídos nos municípios de Araquari (1), Armazém (1), Caçador (1), Florianópolis (2), Jaraguá do Sul (1), Joaçaba (2), Joinville (1), Lindóia do Sul (1), Pomerode (1), São José (3), São Ludgero (1) e Taió (1). Esse estado também apresentou as maiores taxas de anafilaxia por doses distribuídas $(2,46)$ e aplicadas $(5,05)$, que ficaram acima do esperado.

Com isso, propôs-se a realização de um estudo analítico no Estado de Santa Catarina, a fim de testar a hipótese identificada, em análise descritiva, de que as crianças vacinadas com a SCR do produtor A e que apresentaram APLV tiveram anafilaxia.

Os objetivos desta investigação consistem em descrever os casos de anafilaxia relacionados à vacina SCR do produtor A por tempo, lugar e pessoa, avaliar os possíveis fatores de risco associados à anafilaxia pós-vacina SCR desse produtor e propor recomendações. 


\section{Método}

Realizou-se um estudo analítico do tipo caso-controle não pareado (1:4), no Estado de Santa Catarina. As crianças maiores de um ano a menores de cinco anos que receberam a vacina SCR do produtor A na rotina e na campanha nacional de seguimento contra o sarampo, no período de 14 de julho de 2014 a 12 de janeiro de 2015, e que foram notificadas com anafilaxia foram denominadas casos. Nas mesmas condições, as que não foram notificadas com anafilaxia foram chamadas controles.

O diagnóstico de anafilaxia utilizado para o estudo baseou-se nas seguintes considerações: indispensável o comprometimento de dois ou mais órgãos ou sistemas, incluindo sempre os sistemas cardiovascular e respiratório, bem como sinais e sintomas maiores ou menores e níveis de certeza um ou dois ou três.

Quanto aos sinais e sintomas maiores por sistemas, utilizaram-se: (a) dermatológicos - urticária generalizada ou exantema generalizado; angioedema localizado ou generalizado; prurido generalizado com rash cutâneo; (b) cardiovasculares - hipotensão; sinais de choque (pelo menos três dos seguintes: taquicardia, enchimento capilar maior que três segundos, diminuição da pressão venosa central e diminuição do nível de consciência ou perda de consciência); (c) respiratórios - broncoespasmo; estridor; edema de vias aéreas superiores (lábios, língua, garganta, úvula e laringe); sinais de angústia respiratória (dois ou mais dos seguintes: taquipneia, uso de musculatura acessória, tiragem, cianose e gemência).

Quanto aos sinais e sintomas menores por sistemas, utilizaram-se: (a) dermatológicos - prurido generalizado sem rash cutâneo; sensação de ardência generalizada; urticária no local da aplicação; coceira e vermelhidão nos olhos; (b) cardiovasculares - diminuição da circulação periférica (e, pelo menos, dois dos seguintes: taquicardia, enchimento capilar maior que três segundos, sem hipotensão, diminuição do nível de consciência); (c) respiratórios - tosse seca persistente; rouquidão; dificuldade para respirar sem chiado ou estridor; sensação de aperto na garganta; espirros e rinorreia; (d) gastrointestinais - diarreia; dor abdominal; náuseas e vômitos; (e) laboratório (aumento de mastócitos acima dos valores normais).

No que diz respeito aos níveis de certeza, utilizou-se o seguinte: para todos os níveis de certeza (aparecimento repentino E progressão rápida de sinais e sintomas E comprometimento de múltiplos sistemas - maior que dois); nível um de certeza (maior ou igual a um critério dermatológico maior $\mathrm{E}$ maior ou igual a critério cardiovascular maior E/OU maior ou igual a um critério respiratório maior); nível dois de certeza (maior ou igual a um critério cardiovascular maior E maior ou igual a um critério respiratório maior OU maior ou igual a um critério cardiovascular OU respiratório maior E maior ou igual a um critério menor que compromete mais que um sistema diferente - que não seja o sistema cardiovascular ou respiratório - OU maior ou igual a um critério dermatológico maior E maior ou igual a um critério cardiovascular menor E/OU critério respiratório menor); nível três de certeza (maior ou igual a um critério cardiovascular menor OU critério respiratório menor E maior ou igual a um critério menor de dois ou mais sistemas) 4 .

Os controles foram selecionados por conveniência, a partir da unidade básica de saúde (UBS) onde os casos tinham recebido a vacina. Quando o domicílio da criança não era encontrado, o responsável legal estava ausente ou ainda ocorria recusa do entrevistado, seguia-se para a próxima casa em que havia uma criança que se encaixava na definição de caso, até quatro controles serem encontrados. Nas casas com mais de uma criança, ficou definido como controle aquela em que a carteira de vacinação foi visualizada primeiramente.

A coleta de dados foi feita por meio de um questionário padronizado semiestruturado, elaborado especificamente para a realização deste trabalho. Nesse questionário, havia variáveis referentes às questões sociodemográficas, vacinas aplicadas, lote da vacina, presença de APLV diagnosticada por médico, presença de EAPV anterior, história de alergia alimentar familiar, aleitamento materno, diagnóstico e tratamento de APLV.

Utilizou-se um Consentimento Verbal Esclarecido, o qual era lido para os pais ou responsáveis legais pela criança. Questionou-se se eles concordavam em responder as perguntas apresentadas. Ainda, durante a leitura do Consentimento Verbal Esclarecido, assegurava-se para os pais ou responsáveis que os dados individualizados não seriam divulgados, garantindo-se, assim, o sigilo das informações prestadas por eles. 
Para a análise estatística, utilizou-se o odds ratio (OR) como medida de associação, com intervalo de 95\% de confiança (IC95\%) e nível de 5\% de significância . Para as variáveis categóricas, foi utilizado o teste exato de Fisher e qui-quadrado. Para a análise de dados, foram utilizados os programas Epi Info 7.1.4.0 (Centers for Disease Comtrol and Prevention, Atlanta, Estados Unidos) e Microsoft Office Excel 2010 (Microssoft Corp., Estados Unidos).

Os dados analisados no presente estudo foram obtidos no âmbito das ações de vigilância epidemiológica, de modo que o estudo foi dispensado de apreciação por Comitê de Ética em Pesquisa, em conformidade com a Resolução no 466/2012 do Conselho Nacional de Saúde.

\section{Resultados}

Quinze casos e 60 controles (1:4), em 12 municípios do Estado de Santa Catarina, foram incluídos no estudo. O Município de Lindóia do Sul não participou do estudo, uma vez que a criança que teve anafilaxia mudou-se para outro município e não foi localizada, e um caso não pertencia ao Município de São José, sendo do Município de Palhoça (Tabela 1). Essas crianças foram classificadas como perdas.

Nos casos e controles, foram observadas idades médias de 2,26 anos, com desvio padrão $(\mathrm{DP}=0,96)$ e 2,11 anos $(\mathrm{DP}=1,05)$, respectivamente, e primeiro e terceiro quartis de 1,5 e 3,5 para os casos e controles. Todos os casos e controles residiam na zona urbana dos municípios. Dentre os casos, oito (53,4\%) eram do sexo masculino, e dentre os controles, 36 (60\%).

Foi verificada APLV em oito (10,6\%) crianças. Dentre os casos, sete (46,6\%) apresentaram APLV e, dentre os controles, apenas um (1,6\%). Em 100\% dos casos e controles, apresentou-se diagnóstico médico de APLV (Figura 1). A exclusão do leite de vaca da dieta ocorreu em 100\% dos casos e controles com APLV. Dentre os casos, cinco $(71,4 \%)$ consumiam leite de soja e dois $(28,6 \%)$ consumiam outro tipo de leite que não o leite de vaca.

$\mathrm{Na}$ análise bivariada, referente à anafilaxia e $\mathrm{APLV}$, foi verificado $\mathrm{OR}=51,62$. Com isso, as crianças que apresentaram anafilaxia tiveram 51,62 vezes mais chance de terem APLV em relação àquelas que não apresentaram o evento. Para as variáveis alergia alimentar familiar, aleitamento materno, EAPV anterior e vacinação simultânea, não houve diferenças estatisticamente significativas (Tabela 2).

Todos os casos e controles receberam a vacina do produtor A, o qual foi identificado por meio do cartão de vacina da criança. Com referência aos lotes vacinais, dentre os casos, foram aplicados seis

Tabela 1

Distribuição dos casos e controles vacinados contra sarampo, caxumba e rubéola do produtor A, segundo município de residência. Santa Catarina, Brasil, de julho de 2014 a janeiro de 2015.

\begin{tabular}{lccc}
\hline Nome dos municípios & Casos & Controles & Total \\
\hline Araquari & 1 & 4 & 5 \\
Armazém & 1 & 4 & 5 \\
Caçador & 1 & 4 & 5 \\
Florianópolis & 2 & 8 & 10 \\
Jaraguá do Sul & 1 & 4 & 5 \\
Joaçaba & 2 & 8 & 10 \\
Joinville & 1 & 4 & 5 \\
Palhoça & 1 & 4 & 5 \\
Pomerode & 1 & 4 & 5 \\
São José & 2 & 8 & 10 \\
São Ludgero & 1 & 4 & 5 \\
Taió & 1 & 4 & 5 \\
Total & 15 & 60 & 75 \\
\hline
\end{tabular}




\section{Figura 1}

Casos e controles vacinados contra sarampo, caxumba e rubéola em municípios, segundo alergia à proteína do leite de vaca (APLV). Estado de Santa Catarina, Brasil, julho de 2014 a janeiro de 2015, Brasil.

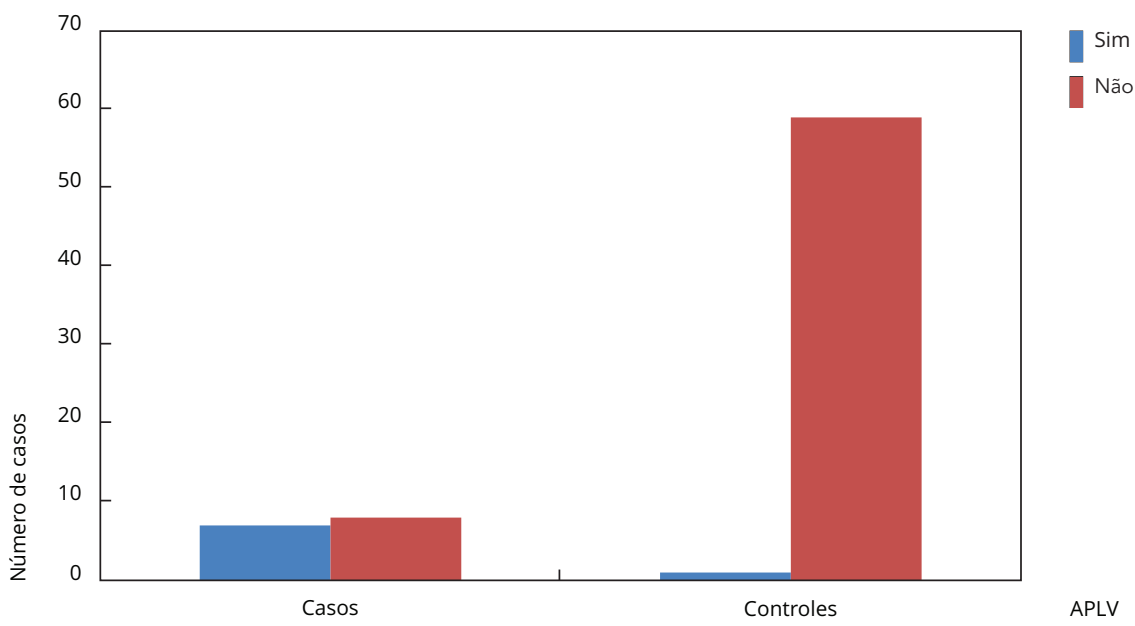

\section{Tabela 2}

Exposições associadas e não associadas à anafilaxia em crianças vacinadas contra sarampo, caxumba e rubéola em municípios. Estado de Santa Catarina, Brasil, de julho de 2014 a janeiro de 2015, Brasil (N = 75).

\begin{tabular}{|c|c|c|c|c|c|}
\hline Exposições & $\begin{array}{l}\text { Casos } \\
(n=15)\end{array}$ & $\begin{array}{l}\text { Controles } \\
(n=60)\end{array}$ & OR & IC95\% & Valor de $p$ * \\
\hline APLV & & & 51,62 & $5,59-476,11$ & 0,00002 \\
\hline Sim & 7 & 1 & & & \\
\hline Não & 8 & 59 & & & \\
\hline Alergia alimentar familiar & & & 1,61 & $0,43-6,05$ & 0,48 \\
\hline Sim & 4 & 11 & & & \\
\hline Não & 11 & 49 & & & \\
\hline Aleitamento materno & & & 0,64 & $0,07-5,78$ & 1,00 \\
\hline Sim & 14 & 54 & & & \\
\hline Não & 1 & 6 & & & \\
\hline EAPV anterior & & & 2,07 & $0,17-24,49$ & 0,49 \\
\hline Sim & 1 & 2 & & & \\
\hline Não & 14 & 58 & & & \\
\hline $\begin{array}{l}\text { Vacina oral contra } \\
\text { poliomielite }\end{array}$ & & & 1,14 & $0,22-5,96$ & 0,61 \\
\hline Sim & 13 & 51 & & & \\
\hline Não & 2 & 9 & & & \\
\hline
\end{tabular}

APLV: alergia à proteína do leite de vaca; EAPV: evento adverso pós-vacinação; IC95\%: intervalo de 95\% de confiança; OR: odds ratio.

* Teste exato de Fisher. 
lotes diferentes, e entre os controles, sete. Não foi possível identificar 12 cartões de vacina da criança ou cartão espelho da UBS, porque não estavam preenchidos ou estavam com o preenchimento incorreto (Tabela 3).

\section{Discussão}

Com base nas informações coletadas em entrevista domiciliar, ocorreram 15 casos de anafilaxia em 12 municípios do Estado de Santa Catarina.

A anafilaxia pode ser causada pela vacinação e é um dos eventos adversos mais graves associados a ela 6. Sua ocorrência é rara, com uma incidência estimada de 0,1-1,0 por 100 mil doses distribuídas 11 . Em relação à SCR, a incidência é de um caso por 100 mil doses aplicadas 7 . As taxas de anafilaxia no estado, quando comparadas à literatura, apresentaram-se acima do esperado, tanto para doses distribuídas quanto aplicadas.

Com relação à idade, a média entre os casos e controles foi semelhante, uma vez que o público participante da campanha encontra-se em uma faixa etária delimitada.

A APLV afeta entre $2 \%$ e 7,5\% das crianças 12,13,14. No estudo, esse percentual foi de 10,6\%, diferindo dos resultados encontrados na literatura.

Um dos principais alimentos responsabilizados por alergia em crianças é o leite, com diagnóstico realizado em bases clínicas 15 . A APLV é uma doença frequente dos lactentes e da infância e ocorre frequentemente nos primeiros anos de vida 12,13,16, corroborando os achados do estudo.

O tratamento das crianças com APLV, referido pelos pais ou responsáveis, consistiu em exclusão do leite da dieta. O diagnóstico da APLV deve ser realizado de forma criteriosa, já que seu tratamento se baseia na exclusão completa do leite de vaca e de seus derivados 14,17,18,19.

No período analisado, devido à concomitância da campanha de vacinação, uma parte considerável das crianças recebeu também uma dose da vacina oral contra poliomietite (VOP). A vacina pode ser administrada de forma segura e eficaz simultaneamente com as vacinas tríplice bacteriana (DPT), dupla (DT), antitetânica (TT), bacilo de Calmette-Guérin (BCG), varicela e VOP 20,21.

Não foi encontrada associação estatística referente a aleitamento materno, história de alergia alimentar familiar e EAPV anterior, corroborando estudos já realizados 22 .

Em 12 crianças, não foi possível identificar o lote da vacina, uma vez que essa informação não constava em seu cartão espelho ou cartão de vacina.

O leite de vaca é frequentemente utilizado em substituição ao leite materno, logo, as suas proteínas são os primeiros alérgenos alimentares com os quais o lactente tem contato, o que o torna o principal

\section{Tabela 3}

Distribuição dos lotes das vacinas entre casos e controles vacinados contra sarampo, caxumba e rubéola em municípios. Estado de Santa Catarina, Brasil, de julho de 2014 a janeiro de 2015.

\begin{tabular}{|c|c|c|}
\hline Lote da vacina & Casos & Controles \\
\hline $015 N 4002$ & 5 & 14 \\
\hline $015 N 4005$ & 4 & 13 \\
\hline 013N3051B & 2 & 5 \\
\hline 013N3051A & 2 & 1 \\
\hline 015N4030B & 1 & 1 \\
\hline $013 N 3013 A$ & 1 & 6 \\
\hline $015 N 4009$ & - & 5 \\
\hline Lote errado * & - & 3 \\
\hline Sem lote & - & 12 \\
\hline Total & 15 & 60 \\
\hline
\end{tabular}

* Lote não foi recebido em Santa Catarina ou não existia. 
alimento envolvido na gênese alimentar 18 . Uma das principais proteínas do leite de vaca implicadas na resposta alérgica é a lactoalbumina, a qual estava presente na composição da vacina. Isso sugere relação do componente na ocorrência da anafilaxia em crianças com APLV, uma vez que foi possível estabelecer estatisticamente essa associação (anafilaxia/APLV).

Como limitação do estudo, pode ter ocorrido viés de memória, uma vez que as mães das crianças que apresentaram anafilaxia após a vacinação tendem a superestimar uma tentativa de explicar a ocorrência do desfecho na recordação de exposições.

Recomenda-se orientar preenchimento do lote, de forma correta, no cartão espelho da unidade de saúde e no cartão de vacina da criança. Também é importante realizar pesquisas que avaliem outras características individuais, além da APLV, que possam ter causado anafilaxia nas crianças vacinadas que não tinham diagnóstico da doença e realizar estudos clínicos para identificar proteínas do leite intactas ou em fragmentos de tamanho suficiente para serem reconhecidos por IgE específicas de pacientes com APLV.

\section{Colaboradores}

F. F. S. T. Fantinato e A. Vargas participaram da concepção e delineamento do estudo, elaboração do questionário, coleta e interpretação dos dados, revisão crítica do conteúdo intelectual do manuscrito, aprovação final da versão a ser publicada e foram responsáveis por todos os aspectos do trabalho. S. M. D. Carvalho e C. M. A. S. Domingues colaboraram na concepção e delineamento do estudo, revisão do questionário, revisão crítica do conteúdo intelectual do manuscrito e aprovação final da versão a ser publicada. G. Barreto, A. S. Fialho e R. H. Silva participaram da concepção e delineamento do estudo, revisão crítica do conteúdo intelectual do manuscrito e aprovação final da versão a ser publicada. E. Saad colaborou na concepção e delineamento do estudo, elaboração do questionário, coleta e interpretação dos dados, revisão crítica do conteúdo intelectual do manuscrito e aprovação final da versão a ser publicada. I. N. S. Agredo contribuiu na concepção e delineamento do estudo, interpretação dos dados e aprovação final da versão a ser publicada e foi responsável por todos os aspectos do trabalho.

\section{Agradecimentos}

À Secretaria de Estado da Saúde de Santa Catarina e às Secretarias Municipais de Saúde.

\section{Referências}

1. Bisetto LHL, Cubas MR, Malucelli A. A prática da enfermagem frente aos eventos adversos pós-vacinação. Rev Esc Enferm USP 2011; 45:1128-34.

2. Araújo TME, Carvalho PMG, Vieira RDF. Análise de eventos adversos pós-vacinais ocorridos em Teresina. Rev Bras Enferm 2007; 60:444-8.

3. Council for International Organizations of Medical Sciences; World Health Organization. Definition and application of terms for vaccine pharmacovigilance. Geneva: World Health Organization; 2012.

4. Ministério da Saúde. Manual de vigilância epidemiológica de eventos adversos pós-vacinação. Brasília: Ministério da Saúde; 2014.

5. Bohlke K, Davis RL, Marcy SM, Braun MM, Destefano F, Black SB, et al. Risk of anaphylaxis after vaccination of children and adolescents. Pediatrics 2003; 112:815-20.

6. Brighton Collaboration Working Group. Standardized cases definition. https://brightoncol laboration.org (acessado em 01/Out/2014).

7. Vanlander A, Hoppenbrouwers K. Anaphylaxis after vaccination of children: review of literature and recommendations for vaccination in child and school health services in Belgium. Vaccine 2014; 32:3147-54.

8. Ministério da Saúde. Manual de normas e procedimentos para vacinação. Brasília: Ministério da Saúde; 2014. 
9. Ministério da Saúde. Campanha nacional de vacinação contra a poliomielite e de seguimento contra o sarampo. Brasília: Ministério da Saúde; 2014

10. Yang A C. A importância de informar a presença de alérgenos alimentares: da rotulagem de alimentos às vacinas. http://www.sbai.org/ secao.asp? $\mathrm{id}=810 \& s=51$ (acessado em $12 / \mathrm{Dez}$ ) 2014).

11. Brotherton JML, Gold MS, Kemp AS, Mclntyre PB, Burgess MA. Anaphylaxis following quadrivalent human papillomavirus vaccination. CMAJ 2008; 179:525-33.

12. Pereira PB, Silva CP. Alergia a proteína do leite de vaca em crianças: repercussão da dieta de exclusão e dieta substitutiva sobre o estado nutricional. Pediatria (São Paulo) 2008; 30:100-6.

13. Chaddad MCC. Direito à informação: proteção dos direitos à saúde e à alimentação da população com alergia alimentar [Tese de Doutorado]. São Paulo: Pontifícia Universidade Católica de São Paulo; 2013.

14. Ferreira CT, Seidman E. Alergia alimentar: atualização prática do ponto de vista gastroenterológico. J Pediatr (Rio J.) 2007; 87:7-20.

15. Santalha M, Correia F, Costa A, Macedo L, Alendouro P, Matos A. Alergia alimentar em idade pediátrica. Nascer Crescer 2013; 22: 75-9.

16. Pereira ACS, Moura SM, Constant PBL. Alergia alimentar: sistema imunológico e principais alimentos envolvidos. Semina Ciênc Biol Saúde 2008; 29:189-200.
17. Solé D, Silva LR, Rosário Filho NA, Sarni ROS Consenso brasileiro sobre alergia alimentar: 2007. Rev Bras Alergia Imunopatol 2008; 31:64-89.

18. Cortez APB, Medeiros LCS, Speridião PG, Mattar RHGM, Fagundes Neto UF, Morais $\mathrm{MB}$. Conhecimento de pediatras e nutricionistas sobre o tratamento da alergia ao leite de vaca no lactente. Rev Paul Pediatr 2007; 25:10613.

19. Weber TK, Speridião PGL, Sdepanian VL, Fagundes Neto U, Morais MB. Desempenho de pais e crianças em dieta de exclusão do leite de vaca na identificação de alimentos industrializados com e sem leite de vaca. J Pediatr (Rio J.) 2007; 83:459-64.

20. Vacina contra sarampo, parotite e rubéola. Nova Deli: Serum Institute of India Ltd.; 2014. Bula.

21. Bricks LF, Sato HK, Oselka GW. Vacinas contra varicela e vacina quádrupla viral. J Pediatr (Rio J.) 2006; 82 Suppl:S101-8.

22. Freitas DRC, Araújo GCB, Cardoso AV, Moura Júnior JE. Investigação de casos de eventos adversos à vacina tríplice viral durante a campanha de seguimento contra sarampo. Relatório final. Brasília: Programa de Treinamento em Epidemiologia Aplicada aos Serviços do Sistema Único de Saúde, Ministério da Saúde; 2004. 


\section{Abstract}

The study aimed to describe cases and verify the frequency of anaphylaxis related to measles, mumps, and rubella (MMR) vaccine produced by manufacturer $A$ and to assess associated risk factors. This was a case-control study (1:4) in Santa Catarina State, Brazil, from July 14, 2014, to January 12, 2015, in children from one year to less than five years of age, vaccinated with MMR and reported with anaphylaxis, while the controls were without anaphylaxis. The measure of association was odds ratio $(O R)$ with $95 \%$ confidence interval (95\% CI), using the chi-square and Fisher's exact tests. Anaphylaxis rates were calculated per doses distributed/administered. Fifteen cases and 60 controls were interviewed in 12 municipalities (counties). Anaphylaxis rates were 2.46 and 5.05 cases per 100,000 doses distributed and administered, respectively. Among the cases of anaphylaxis, eight (53.4\%) were males, and among the controls, 36 (60\%), with $p=0.64$. The bivariate analysis of anaphylaxis and cow's milk protein allergy (CMPA) showed $O R=51.62$, with $p=$ 0.00002 and $95 \%$ CI: $5.59-476.11$. The variables family food allergy, breastfeeding, previous postvaccine adverse event (PVAE), and simultaneous vaccination were not statistically significant $(p=$ $0.48 ; p=1.00 ; p=0.49 ; p=0.61$. Anaphylaxis rates per doses distributed/administered exceeded 1/100,000 doses administered (expected rate). Anaphylaxis and CMPA showed a statistically significant association. No statistically significant associations were found with simultaneous vaccination, breastfeeding, family food allergy, or history of PVAE. Recommendations: the manufacturer should specify the product's components in the package insert, and children with a history of CMPA should not be vaccinated with this vaccine.

Measles-Mumps-Rubella Vaccine; Vaccination; Anaphylaxis; Child

\section{Resumen}

Los objetivos consistieron en describir los casos y verificar la frecuencia de anafilaxia, relacionada con la vacuna del sarampión, paperas y rubeola (SCR) del productor A, así como evaluar los posibles factores de riesgo asociados. Estudio de caso-control (1:4), en Santa Catarina, Brasil, de 14 de julio de 2014 a 12 de enero de 2015, en niños de uno a menores de cinco años, vacunadas con SCR y notificadas con anafilaxia, siendo los controles sin anafilaxia. Se utilizó, como medida de asociación, odds ratio $(O R)$ con un intervalo de 95\% de confianza (IC95\%) y los testes chi-cuadrado y exacto de Fisher. Se calcularon las tasas de anafilaxia por dosis distribuidas/aplicadas. Se entrevistaron 15 casos y 60 controles, en $12 \mathrm{mu}$ nicipios. Las tasas de anafilaxia fueron 2,46y 5,05 por dosis distribuidas y aplicadas, respectivamente. Entre los casos de anafilaxia, ocho $(53,4 \%)$ eran del sexo masculino, $y$ entre los controles, 36 (60\%), con $p=0,64$. En el análisis bivariado referente a la anafilaxia y alergia a la proteina de leche de vaca (APLV), se verificó $O R=51,62$, con $p=0,00002$ e IC95\%: 5,59-476,11. Las variables alergia alimentaria familiar, lactancia materna, evento adverso pos-vacunación (EAPV) anterior y vacunación simultánea no fueron estadísticamente significativas ( $p=0,48 ; p=1,00 ; p=0,49 ; p=$ 0,61 ). Tasas de anafilaxia por dosis distribuidas/ aplicadas se situaron encima de 1/100.000 dosis aplicadas (tasa esperada). Anafilaxia y APLV presentaron una asociación estadísticamente significativa. No fueron encontradas asociaciones estadísticas referentes a la vacunación simultánea, lactancia materna, alergia alimentaria familiar y EAPV anterior. Se recomendó al productor informar en el prospecto sobre todos los componentes del producto, y que los niños con historial anterior de APLV no sean vacunados con esa vacuna.

Vacuna Contra el Sarampión-ParotiditisRubéola; Vacunación; Anafilaxia; Niño
Recebido em 14/Mar/2017

Versão final reapresentada em 06/Out/2017

Aprovado em 24/Out/2017 